\title{
Haematological Malignancies on the Island of Sardinia, 1974-1993: A Geographical Study
}

\author{
Giorgio Broccia ${ }^{1, *}$, Maurizio Longinotti ${ }^{2}$, Barbara Giannico ${ }^{2}$, Caterina Porcu ${ }^{3}$ and Efisio Chessa ${ }^{4}$ \\ ${ }^{I}$ Formerly A. Businco Oncology Hospital, Cagliari, Italy \\ ${ }^{2}$ Institute of Haematology, Sassari University, Sassari, Italy \\ ${ }^{3}$ Department of Internal Medicine, Ospedale San Francesco-Nuoro, Italy \\ ${ }^{4}$ Department of Internal Medicine, Ospedale Delogu-Ghilarza, Italy
}

\begin{abstract}
We studied the geographical distribution of all cases of HM that were diagnosed among residents of Sardinia during the 20-year period from 1974 to 1993.

Cases, grouped into three categories (lymphoproliferative diseases, myeloproliferative diseases, and total haematological malignancies), were assigned to the 356 municipalities of the island according to the reported residence of each patient. In each municipality, the relative risk (RR) of diagnosis was calculated for the three disease groups, for females, for males, and for the total population.

The RR of diagnosis of HM was significantly different from $1(\mathrm{p}<0.05)$ for a limited number of estimates $(5.4 \%)$, with almost as many instances of elevated RR as of reduced RR.

Interested municipalities (87) were distributed unevenly across Sardinia. Nevertheless, we did observe the following:

1) Municipalities with increased risk were mostly situated in central and northern Sardinia, especially for lymphoproliferative diseases in females;

2) One municipality in north-central Sardinia featured numerous estimates of elevated RR;

3) A group of municipalities near the east coast of the island had 1-5 estimates of reduced RR, particularly for lymphoproliferative diseases in females;

4) Only a few municipalities located in areas harbouring potentially polluting activities exhibited increased RRs.

Observed differences in RR, if not due to chance, might be linked to unknown environmental or genetic factors.
\end{abstract}

Keywords: Haematological malignancies, Sardinia, epidemiological study, Lymphoproliferative diseases, Myeloproliferative diseases.

\section{INTRODUCTION}

In a previous paper [1], we described the incidence of haematological malignancies (HM) among residents of Sardinia during the 20-year period from 1974 to 1993. During the study period, we observed an increase in most HM rates. A significant proportion of this increase was probably artifactual and might be linked to improved diagnostic efficiency in the context of easier healthcare access. Indeed, at the end of the study period, incidence rates were stable (with the exception of non-Hodgkin's lymphomas (NHL), acute myeloid leukaemia, and myelodysplastic syndromes, all of which were still increasing); each type of HM had an age and sex distribution as well as corresponding age-world standardised rates (AWSR) that showed only minor differences from those reported for other western countries.

*Address correspondence to this author at the Via Guzzoni degli Ancarani, 609121 Cagliari - Italy; Tel/Fax: 0039070 522992;

E-mail: giorgio.broc@tiscali.it
We analysed the geographic distribution of HMs diagnosed during the 20-year period from 1974 to 1993 to evaluate whether the RR of diagnosis varied across the island. To this end, we used the same, particularly reliable, dataset used in our previous study [1]. Data concerning non-Hodgkin's lymphomas (limited to age $\geq 25$ ) had already been analysed separately [2].

It has long been established that the incidence patterns of many HMs may reveal important geographical differences [3]. It is rare that results of cancer cluster investigations are informative; random variation often remains the most plausible explanation for statistically significant results [4].

Nevertheless, we believed that such a study was worthwhile and opportune. Also, even though the study period was limited to a span from 1974-1993, it was considered that such a study might be used to verify or discount numerous press reports that have indicated increased occurrence of HM in some areas of Sardinia that are linked to potentially polluting activities. These reports, which have raised public con- 
cern, have been partially supported by a study by Biggeri et al. [5].

In addition, we regarded this geographical analysis to be useful for providing reliable results with which to compare future investigations of subsequent study periods.

\section{MATERIALS AND METHODS}

We used the same, particularly reliable, dataset used in our previous study [1], which was based on incident cases recorded by direct consultation of all registries in clinical and pathological institutions operating in Sardinia. For the majority of cases $(>90 \%)$, diagnoses and associated dates were confirmed using cytological and histological reports and clinical records.

From 1974 to 1993, 7,264 HM cases were diagnosed among residents of Sardinia.

Of these, 266 (3.7\%) had to be excluded from the present analysis because information on the specific location in Sardinia was unknown.

Of the remaining 6,998 cases, 2,966 were female and 4,032 were male.

Overall, 5,053 cases (2,215 females and 2,838 males) were diagnosed with lymphoproliferative disease (Lymphopro), specifically acute lymphoblastic leukaemia, chronic lymphocytic leukaemia, multiple myeloma, Hodgkin's lymphoma, non-Hodgkin's lymphomas, Waldenstrom's Macroglobulinemia, Hairy Cell Leukaemia and other 69 cases of undefined lymphoproliferative diseases. A total of 1,853 cases (715 females and 1,138 males) were diagnosed with myeloproliferative disease (myelopro), specifically being acute myeloid leukaemia, myelodysplastic syndromes, chronic myeloid leukaemia, Polycythemia Vera, Essential Thrombocytemia, Myelofibrosis and other 52 cases of undefined myeloproliferative diseases.

Although these two groups included a number of heterogeneous diseases, for the purpose of this analysis we combined them such that the number of cases was sufficiently large to permit statistical analysis.

We analysed these two groups separately as well as a third group of total Haematological Malignancies (Total HM).There were 92 cases of acute leukaemia (36 females and 56 males) that were only included in the THM group because their lymphoid or myeloid origin could not be defined.

Municipalities were chosen as the geographical unit for calculation of relative risks (RR), and their territories were used to generate an island map.

We utilised home addresses as reported in registers and clinical records to assign the observed cases to the $356 \mathrm{mu}-$ nicipalities into which the 1971 Sardinian census (about 1.5 million people) was divided. The municipalities varied in terms of population, ranging from 136 to 233,848 inhabitants (median 1,912) at the time of the 1981 census.

For each municipality, we calculated the relative risk (RR), defined as the ratio between observed and expected cases, for the diagnoses of lymphopro, myelopro and total HM. Data were calculated separately for females, males, and the total population, for a total of 9 calculations for each municipality.

The number of expected cases in each municipality was calculated by applying age- and gender-specific incidence rates of Sardinian total population to the person-years (PY) in corresponding population stratum, and then summing the results over all of the strata.

Statistical significance was evaluated at the $\mathrm{p}<0.05$ level. We used the Episheet software package [6] to calculate RRs, mid-point exact $95 \%$ confidence intervals (CI) and mid-point exact p-values.

\section{RESULTS}

The 3,204 RR estimates (9 from each Sardinian municipality) for HM ranged from 0 to 8.06 , with a mean of 0.89 and a median of 0.85 .

Of the RRs calculated, 174 (5.4\%) were significantly different from $1(p<0.05)$, with elevated or reduced risk in 77 and 97 cases, respectively. Elevated and/or reduced RRs were observed in 87 municipalities; of these, 34 yielded a significantly different RR for only one estimate, whereas 53 municipalities had elevated and/or reduced RRs for 2-7 estimates. In 4 municipalities, multiple occurrences had discordant signs.

Municipalities that exhibited elevated and/or reduced RRs are summarised in Tables $\mathbf{1}$ and $\mathbf{2}$, by gender and disease group. These tables also list the total PYs, total expected and observed cases, and RRs.

Among the 10 Sardinian municipalities with more than 20,000 residents at the time of the 1981 census, 5 showed one or more significantly elevated RR. Thus, Cagliari, the largest town on the island $(233,848$ inhabitants in the 1981 census), presented elevated RR of diagnosis for lymphopro, myelopro, and total HM, both in males and in the total population. The other towns of interest, with populations in the 1981 census shown in parentheses, were Quartu Sant'Elena $(43,896)$, Nuoro $(35,779)$, Olbia $(32,609)$, and Alghero $(36,508)$. These towns showed an increased risk of myelopro in males, lymphopro in females, lymphopro in females and in the total population, and lymphopro in females and in the total population, respectively. One town, Iglesias $(30,119)$, exhibited a significantly reduced risk of total HM in females. No significant difference in risk was observed in Sassari $(119,596)$, Carbonia $(32,180)$, Oristano $(29,424)$, or Portotorres $(20,990)$.

With the exception of the towns reported above, most of the identified municipalities exhibiting significant differences in RR were small villages, and the differences between the observed and expected number of cases were quite modest.

During the period 1974-1993, a certain municipality in the central northern part of the island included an outlying village that was later split off in 1996. In the combined population from 1974 to 1993, seven significantly increased RRs were observed among the nine parameters examined; these included lymphopro in females and in the total population, myelopro in males and in the total population, and total HM in females, in males, and in the total population. However, 
Table 1. Sardinian Municipalities Presenting Statistically Significant Differences in Relative Risk of Diagnosis of Haematological Malignancies, 1974-1993

\begin{tabular}{|c|c|c|c|c|c|}
\hline \multicolumn{6}{|l|}{ Females } \\
\hline & $\begin{array}{l}\text { Municipalities } \\
\text { Number }\end{array}$ & $\begin{array}{l}\text { PY x } 10^{3} \\
\text { Total Range/Median }\end{array}$ & $\begin{array}{l}\text { Obs. Cases } \\
\text { Total Range/Median }\end{array}$ & $\begin{array}{l}\text { Exp. cases } \\
\text { Total Range/Median }\end{array}$ & $\begin{array}{l}\text { Rel. Risk } \\
\text { Range/Median }\end{array}$ \\
\hline $\begin{array}{l}\text { Lymphopro } \\
\text { RR }+\end{array}$ & 18 & $\begin{array}{l}1.668 \\
3,7-373 / 0,7\end{array}$ & $\begin{array}{l}373 \\
3-75 / 11\end{array}$ & $\begin{array}{l}229 \\
0,68-52 / 4,5\end{array}$ & $4,4-1,3 / 2,4$ \\
\hline $\begin{array}{l}\text { Lymphopro Total } \\
\text { Sardinia }\end{array}$ & 356 & $\begin{array}{l}16.134 \\
1-2.369 / 19\end{array}$ & $\begin{array}{l}2.215 \\
0-329 / 3\end{array}$ & & \\
\hline $\begin{array}{l}\text { Lymphopro } \\
\text { RR - }\end{array}$ & 10 & $\begin{array}{l}503 \\
17,5-99,3 / 42\end{array}$ & $\begin{array}{l}20 \\
0-6 / 1\end{array}$ & $\begin{array}{l}74 \\
3,1-13,5 / 6,8\end{array}$ & $0-0,4 / 0,16$ \\
\hline $\begin{array}{l}\text { Myelopro } \\
\text { RR + }\end{array}$ & 7 & $\begin{array}{l}200 \\
11-57.6 / 27\end{array}$ & $\begin{array}{l}35 \\
3-9 / 4\end{array}$ & $\begin{array}{l}10 \\
0.56-2.37 / 1.2\end{array}$ & $5.3-2.5 / 4$ \\
\hline $\begin{array}{l}\text { Myelopro } \\
\text { Total Sardinia }\end{array}$ & 356 & $\begin{array}{l}16,134 \\
1-2,369 / 19\end{array}$ & $\begin{array}{l}715 \\
0-113 / 1\end{array}$ & & \\
\hline $\begin{array}{l}\text { Total HM } \\
\mathrm{RR}+\end{array}$ & 12 & $\begin{array}{l}780 \\
10-373 / 28\end{array}$ & $\begin{array}{l}245 \\
7-89 / 12 \\
\end{array}$ & $\begin{array}{l}151 \\
2.3-70 / 6\end{array}$ & $3.4-1.3 / 2$ \\
\hline $\begin{array}{l}\text { Total HM } \\
\text { Total Sardinia }\end{array}$ & 356 & $\begin{array}{l}16,134 \\
1-2,369 / 19\end{array}$ & $\begin{array}{l}2,966 \\
0-446 / 3\end{array}$ & & \\
\hline $\begin{array}{l}\text { Total HM } \\
\text { RR - }\end{array}$ & 17 & $\begin{array}{l}1,012 \\
17-303 / 32\end{array}$ & $\begin{array}{l}86 \\
0-38 / 1\end{array}$ & $\begin{array}{l}193 \\
2.6-56 / 5.2\end{array}$ & $0-0.7 / 0.18$ \\
\hline
\end{tabular}

Table 2. Sardinian Municipalities Presenting Statistically Significant Differences in Relative Risk of Diagnosis of Haematological Malignancies, 1974-1993

\begin{tabular}{|c|c|c|c|c|c|}
\hline \multicolumn{6}{|l|}{ Males } \\
\hline & $\begin{array}{l}\text { Municipalities } \\
\text { Number }\end{array}$ & $\begin{array}{l}\text { PY } \times 10^{3} \\
\text { Total Range/Median }\end{array}$ & $\begin{array}{l}\text { Obs. Cases } \\
\text { Total Range/Median }\end{array}$ & $\begin{array}{l}\text { Exp. Cases } \\
\text { Total Range/Median }\end{array}$ & $\begin{array}{l}\text { Rel. Risk } \\
\text { Range/Median }\end{array}$ \\
\hline $\begin{array}{l}\text { Lymphopro } \\
\text { RR + }\end{array}$ & $\begin{array}{l}6 \\
+ \\
\text { Cagliari } \\
\end{array}$ & $\begin{array}{l}216 \\
10-111 / 22,1 \\
2.188\end{array}$ & $\begin{array}{l}83 \\
6-30 / 12 \\
446\end{array}$ & $\begin{array}{l}44 \\
2,34-20 / 52 \\
382\end{array}$ & $\begin{array}{l}2,55-1,46 / 2,2 \\
1,17\end{array}$ \\
\hline $\begin{array}{l}\text { Lymphopro } \\
\text { RR - }\end{array}$ & 7 & $\begin{array}{l}292 \\
16,2-82 / 28,9\end{array}$ & $\begin{array}{l}13 \\
0-7 / 0\end{array}$ & $\begin{array}{l}55 \\
3,8-14,4 / 5,4\end{array}$ & $0-0,48 / 0$ \\
\hline $\begin{array}{l}\text { Myelopro } \\
\text { RR + }\end{array}$ & $\begin{array}{l}8 \\
+ \\
\text { Cagliari } \\
\end{array}$ & $\begin{array}{l}826 \\
11-476 / 49.5 \\
2,188\end{array}$ & $\begin{array}{l}102 \\
4-37 / 8.5 \\
189\end{array}$ & $\begin{array}{l}53 \\
1-26 / 3.3 \\
147\end{array}$ & $\begin{array}{l}3.8-1.4 / 2.5 \\
1.28\end{array}$ \\
\hline $\begin{array}{l}\text { Total HM } \\
\text { RR }+\end{array}$ & $\begin{array}{l}4 \\
+ \\
\text { Cagliari } \\
\end{array}$ & $\begin{array}{l}110 \\
7-63.4 / 19.7 \\
2,188\end{array}$ & $\begin{array}{l}69 \\
6-33 / 15 \\
643\end{array}$ & $\begin{array}{l}37 \\
2-18.9 / 7.8 \\
536\end{array}$ & $\begin{array}{l}2.9-1.7 / 1.9 \\
1.19\end{array}$ \\
\hline $\begin{array}{l}\text { Total HM } \\
\text { Total Sardinia }\end{array}$ & 356 & $\begin{array}{l}15,767 \\
1-2,188 / 19\end{array}$ & $\begin{array}{l}4,032 \\
0-643 / 5\end{array}$ & & \\
\hline $\begin{array}{l}\text { Total HM } \\
\text { RR - }\end{array}$ & 13 & $\begin{array}{l}417 \\
9.9-108 / 18.2\end{array}$ & $\begin{array}{l}40 \\
0-15 / 1\end{array}$ & $\begin{array}{l}112 \\
3.18-25 / 5.4\end{array}$ & $0-0.59 / 0.19$ \\
\hline
\end{tabular}




\section{Total Hematological Malignancies}

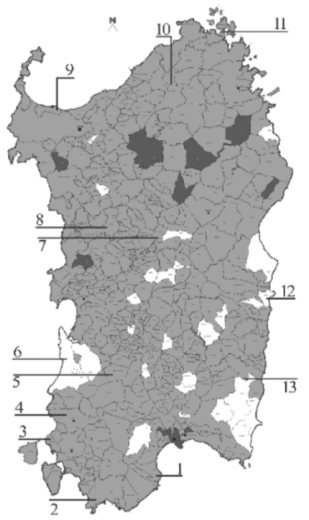

a) Total Population

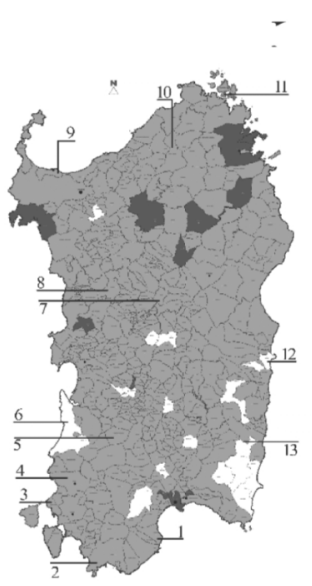

a) Total Population

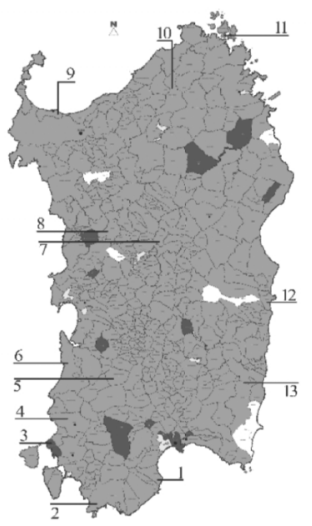

a) Total Population

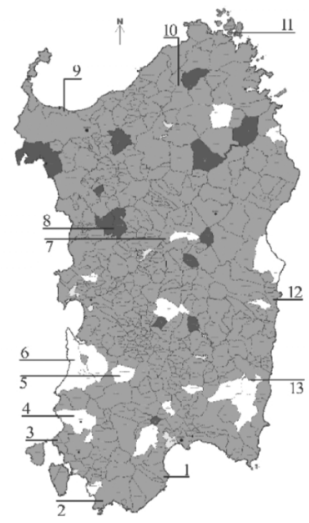

b) Female Population

\section{Lymphoproliferative diseases}

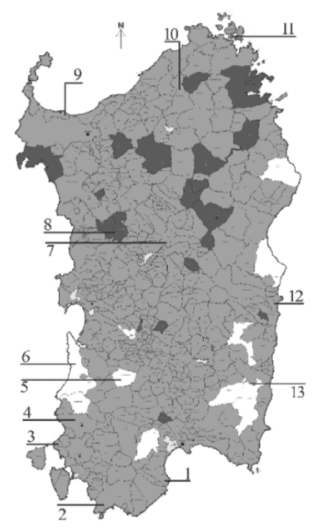

b) Female Population

\section{Myeloproliferative diseases}

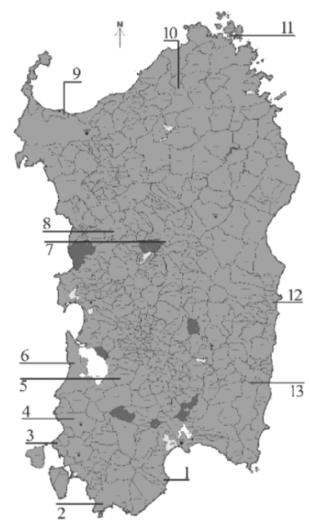

b) Female Population

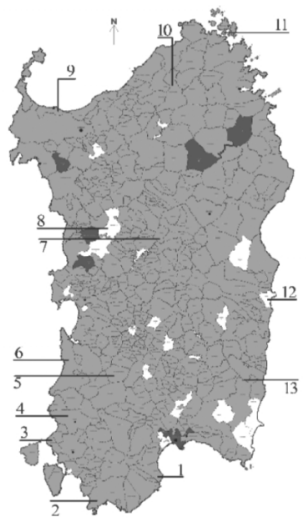

c) Male Population

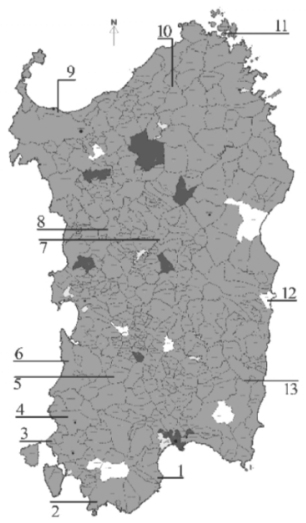

c) Male Population

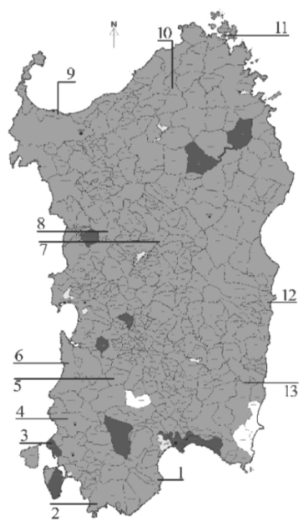

c) Male Population

Fig. (1). Geographic distribution of statistically significant differences in Relative risk of diagnosis of Haematological Malignancies in Sardinian municipalities, 1974-1993.

Sardinian land is divided into territories of the 356 municipalities defined in the 1971 census.

The numbers refer to territories that harbour potentially polluting activities:

Mining activities: Iglesias (ID\# 4): extraction of zinc, lead, silver; Arbus (ID\# 6): extraction of zinc, lead, silver

Military activities: Teulada (ID\# 2); Salto di Quirra (ID\# 13); La Maddalena (ID\# 11)

Industrial activities: Sarroch (ID\# 1): petrochemical and oil refineries; Portoscuso (ID\# 3): aluminium processing; San Gavino (ID\# 5): lead and zinc foundries; Ottana (ID\# 7): chemicals manufacturing; Porto Torres (ID\# 9): petrochemical, chemical and ATT refinery plants; Tortoli (ID\# 12): paper processing; Tempio Pausania (I.D.\# 10): cork ATT production and stone quarries; Macomer (ID\# 8): textile manufacturing.

Darker regions correspond to territories with significantly elevated RRs, while the lighter regions correspond to territories with significantly lower RRs. 
the specific contributions of each of the two populations, administratively split off in 1996, cannot be distinguished.

The maps of RRs by municipality are shown in Fig. (1), categorised by disease group and gender. The maps also indicate Sardinian territories that harbour potentially polluting activities.

Close inspection of the geographical distribution of the municipalities exhibiting elevated and/or reduced RRs revealed that they were not uniformly spread across the island and did not evidence any clear relationship with Sardinian geographic characteristics. Moreover, municipalities with elevated and reduced risks were sometimes geographically contiguous. This was the case for lymphopro, myelopro, and total HM, for both genders and in the total population.

Nevertheless, as previously observed for NHL [2], municipalities with an elevated risk were more likely to be situated in central and northern Sardinia, particularly for lymphopro in females.

Of potential relevance, a group of municipalities near the east coast of the island displayed 1-5 occurrences of reduced $\mathrm{RR}$, particularly for lymphopro in females.

Specific analysis of municipalities near potentially polluting activities revealed the following:

1) Near mining activities (ID\# 4 and 6), none of the municipalities presented an elevated RR, but reduced RR was often observed, most frequently for lymphopro in females;

2) Near military installations (ID\# 2.11 and 13), none of the municipalities showed an elevated RR, whereas reduced RR for lymphopro and total HM in females was found in some municipalities near Salto di Quirra (ID\# 13);

3) Near industrial activities, seven municipalities presented elevated RRs for a total of 10 such instances. These municipalities included: 2 near ID\# 3, 1 near ID\# 7, 1 near ID\# 12, 1 near ID\# 10, and 2 near ID\# 8. The observed RRs ranged from 1.51 to 3.18 with a median of 2.2 , and the number of excess cases ranged from 11.2 to 3.5 , with a median of 5.95 .

In contrast, no significant RRs were evident near industrial activities D\#5, ID\#3, and ID\#1.

\section{DISCUSSION AND CONCLUSION}

Several limitations exist for our analysis. Most arise from our analysis of a relatively small number of cases due to the low incidence of HM and the small population of Sardinia, which, moreover, is dispersed across many municipalities with widely varying populations.

We were only partially able to overcome this drawback.

Case information was collected over a period of 20 years; although the pollution sources had long existed, the extended duration of this study introduces the risk of variations in other environmental factors and lifestyle habits.

To ensure that there was an adequate number of HM cases for statistical analysis, we combined heterogeneous disease categories into three groups (lymphopro, myelopro and total HM); this is a limitation because individual diseases may be well associated with different risk factors that can no longer be discerned when the diseases are grouped.

Another important limitation arises from the fact that our statistical analysis can unlikely evidence statistically significant RR in the less populated municipalities due to their small number of expected cases. However, we believe that some conclusions, although preliminary, can still be drawn from our data.

Firstly, we found that significantly elevated or reduced RRs for HM were evident only in a limited number of locations (about 5\%), with almost identical numbers of elevated and reduced RR values. Municipalities with elevated and/or reduced RRs were distributed in a non-uniform pattern across the island. Moreover, municipalities with elevated and reduced RRs were frequently contiguous.

These findings suggest that the observed differences might be at least partially due to chance alone.

Analysis of geographic distribution reveals that, as previously observed for NHL [2], municipalities with an increased risk profile were more likely to be situated in central and northern Sardinia, especially for lymphopro in females.

Additionally, municipalities near the east coast of Sardinia specifically exhibited multiple occurrences of decreased RR, particularly for lymphopro in females.

The principal aim of this study was to evaluate the RR of diagnosis of HM in Sardinian regions that might be polluted by mining, industrial, or military activities. From 1974 to 1993, statistically significant elevations in RRs were evident, but rare. Only seven such municipalities were in the vicinity of industrial activities. In contrast, RRs were normal or even reduced for all other municipalities near military, mining, and other industrial activities.

These findings are at odds with press reports that have indicated an excess of HM cases in certain industrial and military areas.

Recently, Biggeri et al. [5] reported increased lymphohaemopoietic cancers in males and females in the Porto Torres industrial area (ID\# 9), higher mortality rates and hospital discharges for NHL in males and females in the military area of La Maddalena (ID\# 11), and a non-significant increase in mortality rates and hospital discharges for lymphohaemopoietic cancers in the military area of Salto di Quirra (ID\# 13). The present study failed to detect such findings.

However, our results, which derive from the incidence of HM from 1974 to 1993 in distinct municipalities, cannot be compared with those of Biggeri et al., derived from mortality data from 1997-2001 and prevalence data from 2001-2003; the data of Biggeri et al. also considered larger geographic areas. Moreover, HM were defined differently and a different statistical approach was used.

We cannot establish at present whether the observed statistically significant RRs were due to random variation or are at least partially the result of environmental and/or genetic factors. Furthermore, we cannot rule out the possibility that local variability of documented improvements in healthcare 
access and HM diagnostic efficiency [1] might have contributed to the observed differences in RR of diagnosis.

To conclude : our findings do not confirm the reported excess of HM cases in areas of Sardinia potentially polluted; however, it should be noted that our results are preliminary, thus epidemiologic surveillance should be continued. We are currently conducting an investigation that has extended the case collection period by one more decade, i.e., 19942003. This extension will increase the number of cases and also provide a better understanding of temporal variations. We hope to overcome some of the limitations of the present study and better clarify the significance of the present findings.

\section{ACKNOWLEDGEMENTS}

We are grateful to those who collaborated with us to allow the collection of case information.

Our MS-DOS database software was engineered in 1995 by M.Z. and R.A. Although now outdated, it is still maintained by Mario Zoroddu, who provides expert and patient technical support.
We acknowledge Marcello Canu, who prepared the maps of Sardinia.

We did not apply for or receive any financial support for the present research, which was performed exclusively on a voluntary basis and with personal funds.

\section{REFERENCES}

[1] Broccia G, Deplano W, Dessalvi P, et al. Hematologic malignancies in the island of Sardinia, 1974-1993 : age and sex distributions and temporal changes in incidence. Hematol Oncol 2004; 22: 91 109.

[2] Broccia G, Cocco P, Casula P. Incidence of non-Hodgkin's lymphoma and Hodgkin's disease in Sardinia, Italy: 1974-1993. Haematologica 2001; 86: 58-63.

[3] Cartwright MA, Alexander FE, McKinney PA, Ricketts TJ. Leukaemia and lymphoma. An atlas of distribution within areas of England and Wales 1984-1988. London: Leukemia Research Fund 1990

[4] Thun MJ, Sinks T. Understanding cancer clusters. CA Cancer J Clin 2004; 54: 273-80

[5] Biggeri A, Lagazio C, Catelan D, Pirastu R, Casson F, Terracini B. Enviroment and health in high risk areas of Sardinia, Italy. Epidemiol Prev 2006; 30: 1-96.

[6] Episheet 2002, 2008, by Ken Rothman - Version June 11, 2008 Available from: http://members.aol.com/krothman.modepi.htm. Contacted July 1, 2008. 